
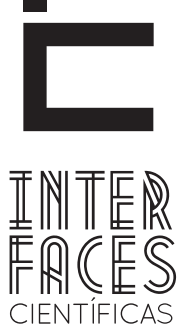

DIREITO

\title{
UM ESTUDO BIBLIOMÉTRICO SOBRE DIREITO DO CONSUMIDOR
}

Alamir Costa Louro ${ }^{1}$

\section{RESUMO}

Na evolução do surgimento dos Direitos (VASAK, 1982), sua terceira geração, ou dimensão, que são aqueles que buscam tutelar direitos coletivos e difusos, o 'Direito do Consumidor' é historicamente destaque. Já 'Consumidor' é um tema mundialmente estudado por distintas áreas do conhecimento humano, carregando em si várias interpretações e possibilidades epistemológicas que nesse artigo serão discutidas sucintamente. No Brasil, a relevância desses assuntos se repete. Assim sendo, este artigo possui o objetivo de efetivar um levantamento sobre pesquisas publicadas inicialmente em periódicos acadêmicos e posteriormente, e de forma mais efetiva, no maior site sobre a área de conhecimento "Direito" no Brasil, foram encontra- dos artigos postados nos últimos 17 anos. Para tal, utilizou-se o método descritivo e bibliográfico, com abordagem quantitativa. Após a análise dos dados, foi possível observar a relevância da necessidade de uma discussão mais acadêmica sobre Direito do Consumidor. Concomitantemente a isso, uma predominância dos princípios como assunto relacionado pode indicar uma incipiência da discussão acadêmica.

\section{PALAVRAS-CHAVE}

Estudo Bibliométrico. Consumo. Direito do Consumidor. Sociologia. 


\section{ABSTRACT}

In the evolution of the emergence of Rights (Vasak, 1982), its third generation, or dimension, which are those that seek to protect collective and diffuse rights, the 'Consumer Law' is historically prominent. Already 'Consumer' is a topic studied worldwide by different areas of human knowledge, carrying itself several interpretations and epistemological possibilities that this article will be discussed briefly. In Brazil, the relevance of these issues is repeated. Therefore, this article has the aim of carrying out a survey on research first published in academic journals and later, and more effectively, the largest site on the area of knowledge "law" in Brazil, found articles posted in the last 17 years. To do this, we used the descriptive and bibliographic method, with a quantitative approach. After analyzing the data, we observed the importance of the need for a more academic discussion of Consumer Law. Concurrently with this, a predominance of the principles as related subject may indicate an incipient academic discussion.

\section{KEYWORDS}

Bibliometric Study. Consumption. Consumer Law. Sociology.

\section{RESUMEN}

En la evolución del origen de los Derechos (VASAK, 1982), su tercera generación, o dimensión, que son las que buscan proteger los derechos colectivos y difusos, el 'Derecho del Consumidor' se pone de relieve históricamente. Ya 'Consumidor' es un tema estudiado en todo el mundo por diferentes áreas del conocimiento humano, que lleva en el él diversas interpretaciones y posibilidades epistemológicas que este artículo serán discutidas brevemente. En Brasil, se repite la importancia de estos temas. Por lo tanto, este trabajo tiene el objetivo de llevar a cabo un estudio sobre investigaciones publicadas en las revistas académicas y posteriormente, y de forma más eficaz, en el sitio electrónico más conocido del área de la "ley" en Brasil, donde se encontraron artículos publicados en los últimos 17 años. Con este fin, se utilizó el método descriptivo y bibliográfico, con un enfoque cuantitativo. Después de analizar los datos, se observó la importancia de la necesidad de un debate más académico sobre Derecho del Consumidor. Paralelamente a esto, un predominio de los principios como tema relacionado puede indicar una falta de la discusión académica.

\section{PALABRAS CLAVE}

Estudio bibliométrico; Consumo; Derecho del Consumidor; Sociología. 


\section{INTRODUÇ̄̃O}

Pode-se situar a disciplina Direito do Consumidor surgindo no meado do século passado, lógico que, assim como em outros direitos, ocorreu a necessidade do direito que ele pretende tutelar lhe é anterior. Tentativas de autotutela e de interferências de terceiros diferentes do estado também, provavelmente, tentaram se viabilizar durante esse processo, mas a edição de princípios e normas segue como forma de tentativa de resolução dos conflitos pessoais na relação do consumo.

Muito aceita pela doutrina, a teoria de classificação dos direitos quanto à geração, ou dimensão, é comumente usada e no presente trabalho é adotada. Como um direito difuso ou coletivo, o direito do consumidor encontra na doutrina de Cláudia Lima Marques forte embasamento, e pedra angular, para as discussões deste artigo.

Mediante a ampla dimensão do interesse pelo 'consumo' - como também pelo 'direito do consumidor' propriamente dito - é natural que um consenso, a respeito de ambos, tenha necessidade de aflorar e, por conseguinte, avançar nas pesquisas que remetam aos seus peculiares meandros e seus relevantes efeitos na sociedade contemporânea.

Este artigo possui como finalidade traçar o perfil dos artigos publicados na internet sobre Direito do Consumidor, tal abordagem é uma tentativa de concretização da busca por um consenso sobre o que se falou nos últimos anos, anos esses evidentemente influenciados pelo advento do Código de Defesa do Consumidor (CDC) de 1990. Para tal foram coletados artigos entre os anos de 1997 e 2014, os quais possuam a frase-chave: "Direito do Consumidor".

Também foram pesquisadas informações no site do Órgão de Proteção e Defesa do Consumidor (Procon) e de súmulas do STJ. Antes de tais levantamentos, mas alinhado com seus resultados, foram traçadas reflexões sob alguns pontos de vistas relacionados com a teoria crítica e com o pós-modernismo.

0 trabalho objetivou realizar uma reflexão sobre a problemática do Consumo na pós-modernidade e sob a ótica da teoria crítica, referenciando alguns importantes autores nacionais e internacionais não relacionados a doutrinas jurídicas de forma a abarcar visões mais amplas e menos pragmáticas, situando o Direito do Consumidor na problemática do Consumo. Apontando para uma possível crise jurídica gerada pela desconstrução de conhecimentos jurídicos há muito tempo institucionalizados.

Como parte do procedimento foi realizada uma pesquisa, usando de Periódicos de circulação nacional com classificação $A 1$ até $C$ do QUALIS-CAPES, mas se mostrou improdutivo e de difícil extração de uma base de dados relevante, o que sugere uma grande oportunidade para se estreitar o relacionamento entre a realidade social e a academia.

\section{PLATAFORMA TEÓRICA}

Como explica (MARQUES, 2002) com o advento da sociedade do consumo massificada e seu individualismo crescente nasce uma crise sociológica denominada por alguns de pós-moderna. A autora fala do ceticismo quanto à capacidade da ciência do direito para dar respostas às questões da sociedade atual.

Segundo a análise de Rosenau (1992, p. 124) sobre a aplicação da desconstrução e da interpretação pós-moderna especificamente na área da teoria jurídica tem-se, com adaptações:

Teoria jurídica é uma arena onde as visões pós-moderna, da epistemologia e o método da desconstrução, criou uma das mais graves crises intelectuais, questionando a própria legitimidade dos sistemas judiciais e a integridade de estudos jurídicos. Historicamente o Direito foi assumido neutro, justo, uma maneira incontroversa de resolver disputas de forma impessoal, formal, previsível e incontestável. A interpretação pós-moderna e a desconstrução podem colocar esses pressupostos de cabeça para baixo, eles argumentam que não há nenhum significado definitivo na lei e questionam a possibilidade de qualquer verdade baseada na razão no campo do Direito. Para a afirmativa pós-modernista, a lei é política, subjetiva, controversa, mera interpretação pessoal. 
"Desconstrução" nessa passagem é entendida como um método de análise pós-moderna onde o objetivo é desfazer as construções, revelando as contradições e suposições sobre determinado conceito, não necessariamente para melhorar o conceito. Tal método parece ser de imensa valia para o jurista que tem preocupações com a ética e a justiça, que parecem ter um embasamento muito mais complexo do que normalmente é visto. Na presente monografia não serão apontados os atores e as causas de uma possível visão míope jurídica.

De forma juvenil é possível se cogitar até uma crítica à representatividade do atual Estado de Direito quando se associa a consideração anterior de Rosenau (1992) com a ponderação da ética, da justiça e do Estado de Bauman (1998):

A ética não é um derivado do Estado. A autoridade ética não deriva dos poderes do Estado para legislar e fazer cumprir a Lei. Ela precede o Estado, é a exclusiva fonte da legitimidade do Estado e o supremo juiz dessa legitimidade. 0 Estado poder-se-ia dizer, só é justificável como veículo ou instrumento da ética.

Isto é, o Estado seria uma consequência da ética do momento. Tal cogitação pode ser apontada como juvenil porque para Bauman (1998) a justiça requer o estabelecimento do Estado, dessa forma há a necessidade da redução da singularidade humana à condição de cidadão, para esse autor a justiça é concebida no encontro entre a experiência da singularidade e a experiência da multiplicidade de outros seres humanos. Nesse momento é importante destacar o consumo como foco importante da tutela, e para tal o estado de direito é de suma importância.

Resumidamente, essas duas abordagens, teoria crítica e pós-modernismo surgem do esgotamento do projeto modernista e da crítica à primazia da razão; elas têm como inimigos o positivismo, a noção de progresso e formas sofisticadas de controle; a desilusão com o projeto modernista é tanto maior quanto a constatação de sua incapacidade de explicar e controlar o mundo.

Não é fácil a tarefa de se conceituar o pós-modernismo, levando em consideração que determinadas correntes sociológicas (pós-estruturalismo) negam a existência de tal termo epistemologicamente atribuindo-lhe apenas conotação histórica.

Antes de adentrar ao pós-modernismo é necessário situar o modernismo como um termo relacionado à filosofia iluminista do século XVIII, que superficialmente conceituando, tem como características a visão do homem acreditando na existência de crescimento, na existência de uma evolução (econômica, pessoal, no conhecimento etc.), são conceitos relacionados com homens serem melhores devido à razão. Isto é, busca-se a perfeição pelo pensamento racional. Nesse contexto, o direito seria tratado como uma forma de instrumento ou de emancipação do homem?

O Pós-modernismo rompe com as ideias modernistas e suas referências absolutas. 0 homem não tem razão. É possível, a partir desse posicionamento, discutir as disciplinas do Direito?

0 questionamento crítico é muitas vezes uma total rejeição do racionalismo etnocêntrico propugnado pelo modernismo. Interpretações mais liberais do direito são vistas como ingênuas por esse tipo de visão crítica. Reflexo de tal visão crítica no campo do direito destaca-se o movimento Critical Legal Studies, capitaniado pelo brasileiro Mangabeira Unger, que pode ajudar na autorreflexão de juristas e eventuais visões instrumentalistas.

0 pós-modernismo pontua-se, dentre outros, sob dois aspectos interessantes de serem pensados especificamente sob a ótica do Direito do Consumidor: a visão de centralidade do discurso de onde se sugere que a pessoa nasça dentro de discursos correntes, há implicações diversas dessa visão da criação social da realidade; outro aspecto interessante é a identidade fragmentada do ser humano.

A palavra 'consumo' carrega em si muitas possibilidades de aprofundamentos acadêmicos segundo cada disciplina observadora. Seu conceito é mais complexo, mas será tratado aqui por ser considerada de suma importância para problematizar o Direito do Consumidor. Já quanto ao Direito do Consumidor uma questão central é o conceito de consumidor. Para o CDC (1990) já em seu artigo segundo tem-se: "Con- 
sumidor é toda pessoa física ou jurídica que adquire ou utiliza produto ou serviço como destinatário final".

Como nos ensina Marques (2002), a partir de tal conceito duas correntes (finalistas e maximalistas) se formaram para interpretar o termo "destinatário final" e analisar o campo de aplicação e amplitude do CDC. Sucintamente, os finalistas são mais objetivos ao tratar o destinatário como apenas aquele que tira o bem do mercado. Já para os maximalistas, que foram acompanhados majoritariamente pela doutrina e jurisprudência, o CDC seria um código geral sobre o consumo, um código para a sociedade de consumo. Isto é, eles ampliam o impacto do CDC. É possível relacionar a corrente maximalista com um menor reducionismo da singularidade humana.

Para a antropóloga Lívia Barbosa (2006), o consumo pode ser considerado algo ambíguo. Essa visão torna ainda mais ampla a interpretação de uma sociedade de consumo da corrente maximalista. Em inúmeras ocasiões, o consumo incorpora o algoz de um processo manipulatório, em outras está simplesmente atrelado ao ato de comprar e toda sorte de querelas jurídicas.

Com uma visão negativista do consumo, Bauman (2004) alerta que bens de diferentes naturezas são jogados no lixo mediante o advento da intensificação da obsolescência programa - elevando, consequentemente, o débito ambiental do planeta, enquanto que Padilha (2006) funde o ser "consumidor" e o ser "cidadão” em um único ente. E, dispara ainda que quem não tem dinheiro, não tem cidadania.

Escolhem-se, utilizam-se, produzem-se e transformam-se os bens mediante objetivos, necessidades e vontades construídas pelos sujeitos, o que pode ser relacionado com o Dogma da Autonomia da Vontade parte da Concepção Tradicional do Contrato (MARQUES, 2002). Destarte a questão da vontade, segundo Don Slater (2002), se de fato o consumo está merguthado em um emaranhado de possibilidades, ao menos é possível afirmar que a subjetividade, tanto no âmbito intelectual quanto prático, é elemento condutor de informação que, inexoravelmente, marca presença nos processos decisórios do consumidor, seja nas pequenas, médias ou grandes deliberações.
Deve ser notada a relação disso com a questão da vulnerabilidade do consumidor. É interessante notar que tal subjetividade é inerente e torna, desta forma, mais complexo o trabalho do Jurista. Pode-se com essa afirmação então entender o porquê da opção pelo o uso de princípios como direcionador do CDC, se mostrando dessa forma a opção mais acertada.

Densas e instigantes são as questões que podem ser elaboradas sobre a temática do Direito do Consumidor, portanto, o afastamento dos métodos e estruturas científicas parece inapropriado, mesmo levando em conta as considerações pós-modernas introduzidas anteriormente. É importante destacar que o método científico nada mais é que regras para observar fenômenos e inferir conclusões a partir de tais observações (MARTINS; THEÓPHILO, 2007).

\section{METODOLOGIA}

Independentemente da discussão sobre a "Teoria Pura do Direito" de Hans Kensel, é possível cogitar a possibilidade de contribuição de uma abordagem científica para a produção do conhecimento na área do Direito. Não se trata de uma proposição de repensar a prática do direito de forma científica, mas de pensar de forma científica a produção de trabalhos acadêmicos.

Este artigo, então, aproveita também para sugerir que a disciplina do direito possa oportunizar primeiramente o prosseguimento de todas as fases da ciência, incluindo pesquisas exploratórias, qualitativas e porque não, quantitativas.

Pode-se enxergar a produção do conhecimento na área do Direito, como precária, se de forma comparativa for verificado que em muitas outras ciências a partir de uma investigação realizada por um indivíduo ou uma equipe pequena, é quase impossível fazer uma contribuição que abrange todas as fases da ciência desde a exploração até a criação da teoria e validação de um modelo para o teste empírico.

0 método que norteou a realização da pesquisa foi descritivo e bibliográfico, com abordagem quantitativa. Do ponto de vista dos seus objetivos, a pesquisa 
é considerada descritiva porque, segundo Gil (1991), propõe-se a descrever características de determinado cenário. Do ponto de vista técnico, a pesquisa é bibliográfica, uma vez que os dados foram extraídos de material publicado no site Jus Navegandi e em periódicos de circulação nacional da área de Direito com classificação de $\mathrm{A} 1$ a $\mathrm{C}$ de acordo com a classificação QUALI-CAPES.

A pesquisa bibliográfica foi realizada, coletando informações por meio de busca eletrônica nos sites SCIELO, Google Acadêmico <scholar.google.com. $\mathrm{br} />$. Foram buscados artigos com a palavra-chave "Direito do Consumidor", e encontrados poucos resultados, o que levou os autores da pesquisa a abarcar o site Jus Navegandi, também, como fonte primária de informação.
Acredita-se que mesmo ignorando os prováveis vieses, pode-se encontrar o que tem se discutido, e quem, sobre o assunto no Brasil mesmo que sem a chancela da academia.

\section{PERFIL DOS ARTIGOS SOBRE DIREITO DO CONSUMIDOR}

\subsection{FREQUÊNCIA POR AUTORES}

Foram identificadas apenas essas três repetições de autores, todos os outros publicaram apenas um artigo. Aproveitou-se para pesquisar o vínculo acadêmico desses autores destacados, sendo que o método para isso foi realizar uma busca no sistema Lattes.

Tabela 1 - Relação dos autores que mais publicaram

\begin{tabular}{|l|l|l|}
\hline \multicolumn{1}{|c|}{ Autor } & Frequência & \multicolumn{1}{c|}{ Vínculo com a Academia } \\
\hline MARTINS, Plínio Lacerda & 2 & $\begin{array}{l}\text { Mestre em Direito pela Universidade Gama Filho (2001) e professor } \\
\text { na UNIVERSIDADE FEDERAL DE JUIZ DE FORA UFJF } \\
\text { http://lattes.cnpq.br/16435333929253579 }\end{array}$ \\
\hline OLIVEIRA, Celso Marcelo de & 3 & Não encontrado no sistema Lattes \\
\hline ROCHA, Amélia Soares da & 3 & $\begin{array}{l}\text { Mestre em Políticas Públicas e Sociedade (UECE) e Professora-pes- } \\
\text { quisadora da Universidade de Fortaleza (UNIFOR) } \\
\text { http://lattes.cnpq.br/3867147056763751 }\end{array}$ \\
\hline
\end{tabular}

Fonte: dados coletados pelo pesquisador e Sistema Lattes. 


\subsection{FREQUÊNCIA POR AUTORES REFERENCIADOS}

Constatou-se que dentre os quatorze mais citados, quatro são autores do anteprojeto do CDC: Ada Pellegrini Grinover, Antônio Herman de Vasconcellos e Benjamim, José Geraldo Brito Filomeno, Nelson Nery Junior. Com uma abordagem de estatística básica chegou-se às seguintes informações: 0 número de referências bibliográficas foram 432 e autores referenciados foram 265, daí inferiu-se a média aritmética que foi de 1,62 artigos por autor, o que indica que a grande maioria dos autores foi citada apenas uma única vez, demonstrando uma fragmentação.

Na Tabela 2 estão destacados os autores com maior frequência de citações na base de dados.

Tabela 2 - Relação dos Autores que mais foram citados

\begin{tabular}{|l|l|}
\hline \multicolumn{1}{|c|}{ Autores } & \multicolumn{1}{|c|}{ Frequência } \\
\hline ALMEIDA, João Batista de & 5 \\
\hline ALVIM, Arruda & 6 \\
\hline BENJAMIM, Antônio Herman de Vasconcelos & 8 \\
\hline BESSA, Leonardo Boscoe & 5 \\
\hline COMPARATO, Fábio Konder & 5 \\
\hline DINIZ, Maria Helena & 5 \\
\hline FILOMENO, José Brito & 15 \\
\hline GOMES, Orlando & 15 \\
\hline GRINOVER, Ada Pelegrini & 7 \\
\hline MARQUES, Cláudia Lima & 14 \\
\hline MORAES, Alexandre de & 18 \\
\hline NERY JUNIOR, Nelson & 7 \\
\hline NUNES, Luiz Antonio Rizzato & 6 \\
\hline REALE, Miguel & 14 \\
\hline
\end{tabular}

Fonte: dados coletados pelo pesquisador. 
É importante destacar, também, que dentre toda a população de citações a moda estatística é da doutrinadora Cláudia Lima Marques com dezoito recorrências. É necessário destacar que a escolha teórica dessa autora foi coincidente e exercida a priori. É possível destacar que apenas esses 14 autores foram referenciados 120 vezes do montante de 432 citações.

\subsection{FREQUENNCIA POR ASSUNTO RELACIONADO}

\section{Gráfico 1 - Frequência por assunto relacionado}

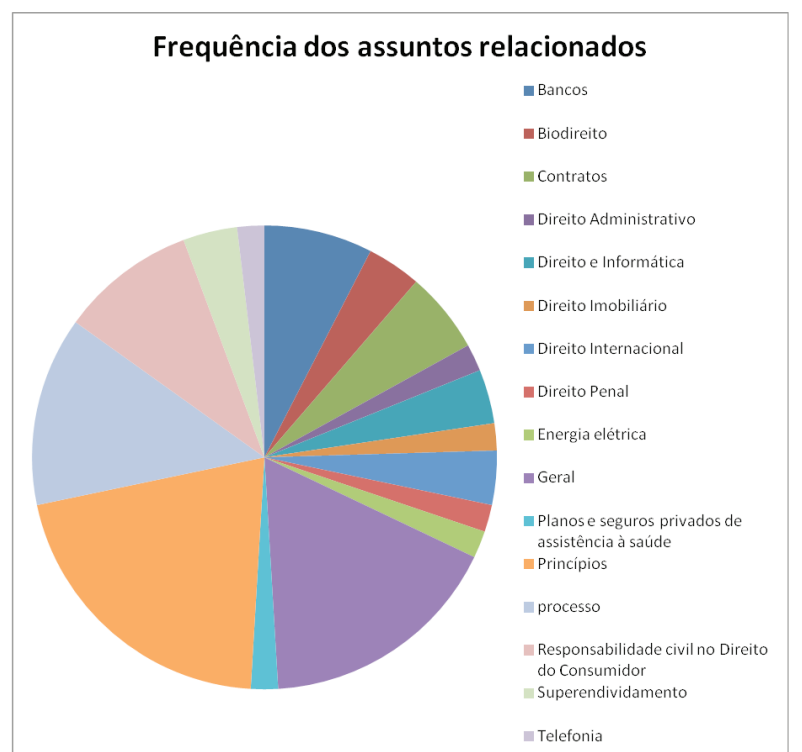

Fonte: dados coletados pelo pesquisador.

Como a classificação é abrangente decidiu-se agrupar os assuntos para melhorar a possibilidade de análise.

Foram agrupados Bancos, Energia elétrica, Planos e seguros de saúde, Telefonia no grupo chamado Fornecedores que representam artigos relativos às mais costumeiras querelas já existentes entre o cidadão e fornecedores específicos, indicando quais são os segmentos que mais geram discussões e que provavelmente mais precisam evoluir quanto ao direito do consumidor. Não coincidentemente esses segmentos de fornecedores são os que se utilizam de contratos de massa e de adesão, sendo esse último um método do contrato de massa. (MARQUES, 2002) introduz o conceito de contrato de massa da seguinte forma:

Na sociedade do consumo, com seu sistema de produção e de distribuição em grande quantidade, o comércio jurídico se despersonalizou e se desmaterializou. Os métodos de contratação em massa, ou estandardizados, predominam em quase todas as relações contratuais entre empresas e consumidores.

O agrupamento Princípios abarca os assuntos: Princípios, Responsabilidade Civil e Processos que se pode acreditar serem os assuntos mais tratados no momento sobre Direito do Consumidor.

Gráfico 2 - Frequência por assuntos (reagrupado)

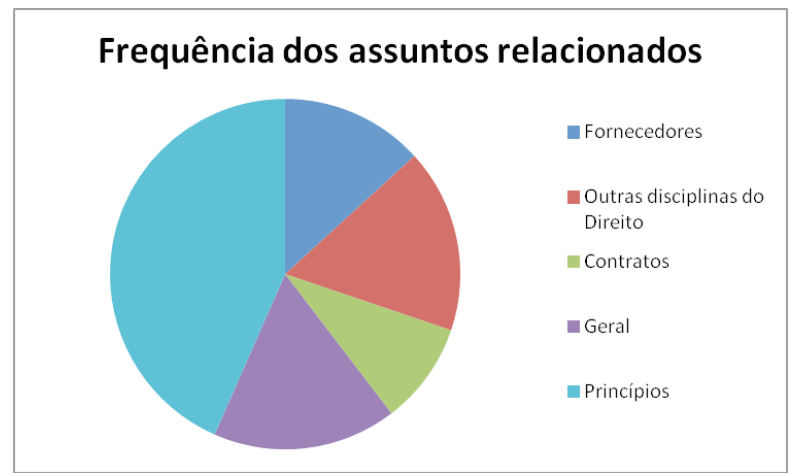

Fonte: dados coletados pelo pesquisador.

É importante relatar o destaque que o agrupamento de Princípios tomou, o que indica a incipiência da discussão sobre Direito do Consumidor.

\subsection{PERFIL DAS RECLAMAÇÕES NO PROCON}

Outra forma de agrupamento interessante é separar apenas os artigos que tratam de fornecedores específicos. 0 motivo de tal classificação artificial é a possibilidade de comparação com dados do Procon, no sentido de ser possível verificar quais são os tipos 
de fornecedores que mais têm reclamado nos últimos tempos. Para tal foi realizada uma busca no site do ministério da justiça no sistema SINDEC que é o sistema nacional de informações de Defesa do Consumidor que integra informações de PROCONs de vinte e quatro estados da federação.

A partir dos dados dos artigos e dos dados do SINDEC, é possível notar a importância dos Bancos (Assuntos financeiros) como principal foco de reclamações. Outro campeão são os serviços essenciais que englobam: água, telefonia, energia elétrica e planos de saúde. Com isso é possível inferir que a produção de artigos não está descolada do foco de reclamações do Procon.

\subsection{PERFIL DAS SÚMULAS DO STJ SOBRE DIREITO DO CONSUMIDOR}

Inicialmente foi feita uma pesquisa no Site das Jurisprudências do STJ para verificar sobre que assuntos elas tratam no que tange ao CDC. A partir da relação completa foi feito o seguinte gráfico sobre os assuntos relacionados. Pode-se concluir que a regulamentação de regras para bancos é o maior foco das súmulas do STJ, o que parece ir ao encontro dos dados levantados, anteriormente, tanto na pesquisa no Procon quanto nos artigos acadêmicos.

Gráfico 3 - Frequência de assuntos das Súmulas

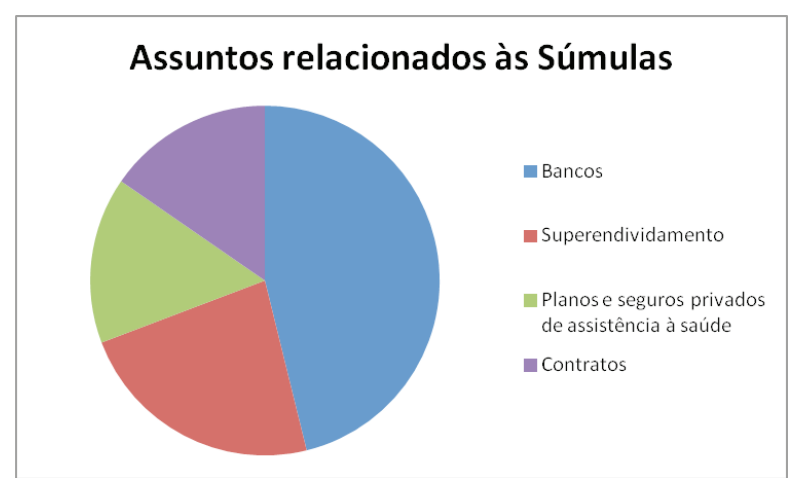

Fonte: Dados coletados do STJ.

\section{CONCLUSÕES}

Algumas conclusões são de fácil compreensão, como por exemplo, a importância dos autores do anteprojeto do CDC, demonstrada pela recorrência das citações da Tabela 2. Também é de compreensão simples a importância dos princípios como assunto relacionado, isso indica tanto o estágio inicial de discussões sobre Direito do Consumidor quanto a forma que foi concebido o CDC, pensado como um sistema e não apenas como uma lei comum, de forma que os princípios sejam a opção de embasamento para argumentações, conseguindo com isso não engessar uma área com tantas possibilidades de problematização hodiernas e que muito ainda precisará evoluir se for levada em consideração a continuidade da grande evolução tecnológica dos últimos anos.

A conclusão que mais necessita de validação e explicação é a falta de artigos ou de acesso aos mesmos em periódicos QUALI-CAPES via internet. Aqui se pode acreditar ser a maior contribuição do presente artigo, porque provavelmente há a grande oportunidade para a produção por parte de acadêmicos do Direito. Ficam algumas perguntas sobre tal situação: Há um distanciamento entre os fatos sociais na área de direito e o método científico? Seria uma diáspora acadêmica ou um distanciamento político ou apenas o fato do conhecimento ainda estar se consolidando?

Uma possibilidade muito interessante de estudos futuros é analisar internacionalmente se existe a mesma falta de artigos acadêmicos sobre Direito do Consumidor.

\section{REFERÊNCIAS}

\section{BARBOSA, L.; CAMPBELL, C. Cultura, consumo e identidade. Rio de Janeiro: FGV, 2006.}

BAUMAN, Zygmunt. Modernidade líquida. Rio de Janeiro: Jorge Zahar, 2004. 
BAUMAN, Zygmunt. 0 mal estar da pósmodernidade. Rio de Janeiro: Jorge Zahar, 1998.

CDC 1990 - Código de Defesa do Consumidor de 1990. Disponível em: <http://www.planalto.gov.br/ ccivil_03/leis/L8078.htm>. Acesso em: 6 abr. 2014.

GIL, Antonio Carlos. Métodos e técnicas de pesquisa social. São Paulo: Atlas, 1999.

GOOGLE ACADÊMICO - Site oficial de buscas de artigos acadêmicos do Google. Disponível em: <http://www.stj.jus.br/SCON/index.jsp>. Acesso em: 1 abr. 2014.

JUS NAVIGANDI - Site oficial do Jus Navigandi. Disponivel em: <http://jus.com.br/> Acesso em: 1 mar. 2014

LATTES - Site de buscas de currículos. Disponível em: <http://buscatextual.cnpq.br/buscatextual/busca. do?metodo=apresentar>. Acesso em: 4 abr. 2014

\section{MARQUES, Cláudia Lima. Contratos no Código de} Defesa do Consumidor: o novo regime das relações contratuais. 4.ed. São Paulo: Revista dos Tribunais, 2002.

MARTINS, Gilberto de Andrade; THEÓPHILO, Carlos Renato. Metodologia da investigação científica para ciências sociais aplicadas. São Paulo: Atlas, 2007.
PADILHA, Valquíria. Shopping Center: a catedral das mercadorias. São Paulo: Boitempo, 2006.

PORTAL MJ - Site oficial do Ministério da Justiça sobre o Sistema Nacional de Informações de Defesa do Consumidor. Disponível em: <http://portal.mj.gov. br/SindecNacional/graficos/SelecionaGraficoForm. jsp?tp=sindec $>$. Acesso em: 6 abr. 2014.

\section{ROSENAU, Pauline M. Post-modernism and the} social sciences insights, inroads, and intrusions. USA: Princeton University Press, 1992.

SLATER, Don. Cultura, consumo e modernidade. São Paulo: Nobel, 2002.

\section{STJ - Site oficial de buscas de jurisprudencia do} STJ. Disponível em: <http://www.stj.jus.br/SCON/ index.jsp>. Acesso em: 20 set. 2014.

\section{VASAK, Karel, The international dimensions of} human rights. Michigan University, USA: Greenwood Press, 1982. 